\title{
Effect of rare element cerium on the morphology and corrosion resistance of electro-less $\mathrm{Ni}-\mathrm{P}$ coatings
}

\author{
Chuan-qi Fu, ${ }^{1, a}$, Fan Yong ${ }^{2}$,Siyuan Wang ${ }^{2}$, Zhou Wang ${ }^{2}$, Qingle Zhang ${ }^{2}$, Xuliang Luo $^{2}$ \\ ${ }^{1}$ Institute of Mechanical Engineering, Dalian University, China \\ ${ }^{2}$ Dalian University Surface Engineering Centre,China
}

\begin{abstract}
This paper reports an experimental study on the microstructure and corrosion resistance of electro-less Ni-P coatings with increasing content of the rare element cerium (Ce). Surface morphology and the composition of the electro-less Ni-P coatings were studied by scanning electron microscope (SEM), X-ray energy dispersed analysis (EDS) and X-ray diffraction analysis (XRD). Hardness and Adhesive force are researched by a HX-200 Vickers diamond indenter micro-hardness tester. Furthermore, we study the adhesive force by using the Revetest scratch tester. We get the possession of Ce amorphous Ni-P coatings which has excellent properties in anti-corrosion. The effect of the rare element cerium concentration on corrosion resistance of the coatings was evaluated in the groundwater immersion test and porosity test, respectively. The results indicated that added little the rare element cerium into the plating bath increased the phosphorus content of the coatings, decreased the corrosion rates, it also decreases the porosity of the amorphous Ni-P coatings. The lowest corrosion rates of the amorphous Ni-P coatings in groundwater immersion test is $4.1 \mathrm{um} \cdot \mathrm{h}^{-1}$, at the rare element cerium concentration of $0.12 \mathrm{~g} \cdot \mathrm{L}^{-1}$

Keywords: electro-less Ni-P coatings; rare element cerium; microstructure; phosphorus content; corrosion resistance; porosity
\end{abstract}

\section{INTRODUCTION}

Electro-less nickel-phosphorus is a chemical processing method that the use of a suitable reducing agent in the solution of nickel ions are selectively activated catalyst surface of the substrate to deposit metallic nickel reduction of the surface coating. Electro-less Ni-P coatings, first developed by Brenner and Riddell, have found extensive use in mechanical, chemical and electronic industries due to their excellent mechanical, physical, electrical, corrosion, and tribological properties ${ }^{[1 \sim 4]}$. As the phosphorous content increase in the Ni-P coating, its surface morphology changes from crystal structure to amorphous structure ${ }^{[5,6]}$. Amorphous electro-less Ni-P coating are formed in deposited process when the phosphorus content is more than $8 \mathrm{wt}$ percent. The specific density of the Ni-P coating in the amorphous phase is smaller than that in the crystalline phase. Amorphous electro-less Ni-P coating has excellent corrosion resistance.

The rare element cerium has special f electronic shell in changing the steels properties. Because of its chemical activity, such as magnetic, optical, and electric and hydrogen storage properties and have successfully been used in metallurgy, electronics and chemical engineering. Researchers have found that can influence on certain parameters like the deposition rate and stability of the

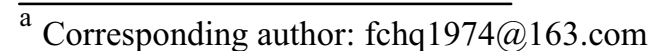

bath in $\mathrm{Cr}, \mathrm{Ni}$, and $\mathrm{Cu}$ electroplating process. It is also reported that added in a small rare element cerium can improve mechanical properties of alloy ${ }^{[7]}$. Under the rare element coordinate action of sexadentate, $5 \mathrm{~d}$ orbits being degenerated in the central ion of rare element cerium are divided into $e_{g}$ group and $t_{2 g}$ group. Higher energy level of the $e_{g}$ group takes in two orbits compared to the original energy state, and the $t_{2 g}$ group which takes in three orbits has lower energy level compared to the original energy state. Most electronic configuration of the rare elements are owned $\mathrm{d}^{0 \sim 2}$, so they are of activation for substitution. The electronic configuration of metal element $\mathrm{Ni}, 4 \mathrm{~d}^{8} 5 \mathrm{~s}^{2}$, the orbits are rich with electron filled, and is not reactivity in activation for substitution[8]. Priority of discharging in activation for substitution of rare element can improve the electrode interface coordination ions in the electro-plating bath.

The experiments, by added different concentration of rare element cerium, mainly study on the Ni-P coating of the surface morphology, hardness and adhesive force, the deposition rates, the phosphorous content and the corrosion resistance in a high morphology program.

\section{EXPERIMENT PROCEDURES}

\subsection{Sample Preparation}


The 45\# carbon steel samples of which the dimensions are about $35 \mathrm{~mm} \times 35 \mathrm{~mm} \times 1.5 \mathrm{~mm}$ were prepared using abrasive papers from 240 to 1000 grade, and then were cleaned sequent in acetone by using ultrasonic rinsing and in concentrated $\mathrm{NaOH}$, activated by acid dip in $10 \%$ $\mathrm{HCl}$. After every step the samples were rinsed in distilled water. In order to obtain composite $\mathrm{Ni}-\mathrm{P}$ coating the following nickel planting bath was prepared as follow, $\mathrm{NiSO}_{4} \cdot 6 \mathrm{H}_{2} \mathrm{O}$ of $30 \mathrm{~g} \cdot \mathrm{L}^{-1}, \mathrm{NaH}_{2} \mathrm{PO}_{2} \cdot \mathrm{H}_{2} \mathrm{O}$ of $36 \mathrm{~g} \cdot \mathrm{L}^{-1}$, $\mathrm{C}_{4} \mathrm{H}_{6} \mathrm{O}_{5}$ of $15 \mathrm{~g} \cdot \mathrm{L}^{-1}, \mathrm{C}_{6} \mathrm{H}_{8} \mathrm{O}_{7} \cdot \mathrm{H}_{2} \mathrm{O}$ of $10 \mathrm{~g} \cdot \mathrm{L}^{-1}$, surfactant (FC-134) of $0.2 \mathrm{~g} \cdot \mathrm{L}^{-1}$, ranging from $0 \sim 0.2 \mathrm{~g} \cdot \mathrm{L}^{-1}$ were the concentration of $\mathrm{CeSO} 4$, respectively. The plating bath had a $\mathrm{pH}$ of $5 \sim 6$, the temperature of plating bath was controlled at $85 \sim 90{ }^{\circ} \mathrm{C}$, plating time $2 \mathrm{~h}$, respectively. After the completed of the plating, clean the sample in deionizied water and dry it.

\subsection{Test equipment and methods}

\subsubsection{Surface morphology and composition}

Surface morphology of the coatings was observed by scanning electron microscope (SEM). X-ray diffraction analysis (XRD) was conducted to characterize crystal structures of the as-deposited coatings. The chemical compositions of the Ni-P coatings were analyzed with an $\mathrm{X}$-ray energy dispersive spectroscope attached in the SEM.

\subsubsection{Corrosion measurements}

The sample of coating had groundwater immersion test for 24 hours respectively, the temperature of the test is $85^{\circ} \mathrm{C}$. The groundwater immersion test solution was prepared as follow, $\mathrm{NaHCO}_{3}$ of $1748.8 \mathrm{mg} \cdot \mathrm{L}^{-1}, \mathrm{NaCl}$ of $2546.1 \mathrm{mg} \cdot \mathrm{L}^{-1}, \mathrm{CaCl}_{2}$ of $322.5 \mathrm{mg} \cdot \mathrm{L}^{-1}, \mathrm{MgCl}_{2}$ of 77.2 $\mathrm{mg} \cdot \mathrm{L}^{-1}$. The corrosion rates of the composites were measured with immersion weight gain method and calculated by the following formula:

$$
v=\frac{m_{1}-m_{2}}{t \cdot A \cdot \rho} \times 10^{4} \times 365
$$

Where $v$ is the corrosion rate of the composites $\left(\mathrm{mg} \cdot \mathrm{cm}^{-2}\right) ; m_{1}$ and $m_{2}$ are the mass of the sample before and after fouling test $(\mathrm{mg}) ; t$ is the deposition time; $A$ is area of the simple $\left(\mathrm{cm}^{2}\right) ; \rho$ is density of the Ni-P coatings, $\rho$ is replaced by $7.9 \mathrm{~g} \cdot \mathrm{cm}^{-3}$.

\subsubsection{Coating porosity}

The blue- brown spots method is used for test of coating porosity. At the room temperature, filter paper which soaked in a solution consist of $15 \mathrm{~g} \cdot \mathrm{L}^{-1} \mathrm{~K}_{3}\left[\mathrm{Fe}(\mathrm{CN})_{6}\right]$ and $25 \mathrm{~g} \cdot \mathrm{L}^{-1} \mathrm{NaCl}$, attached to the sample surface, after 10 min reaction, check the number of the blue- brown spots on the per unit area of the filter paper ${ }^{[11]}$.

\subsubsection{Hardness and Adhesive force}

Hardness of the coatings was measured by using a HX200 Vickers diamond indenter micro-hardness tester with a load of $100 \mathrm{~N}$ and a duration time of $20 \mathrm{~s}$. At least ten indents were performed to gain average hardness value for each sample.

Adhesive force of the coating was tested by the Revetest scratch tester, the load force of the Revetest scratch tester ranges from $1 \mathrm{~N}$ to $200 \mathrm{~N}$. The coatings average adhesion force of each sample was measured three times in the test.

\section{Results and discussion}

\subsection{The composition of the Ni-P coatings}

Fig.1 shows that EDX pattern of the electro-less Ni-P coating on carbon steel with cerium concentration of 0.12 $\mathrm{g} \cdot \mathrm{L}^{-1}$. It is obviously observed that $\mathrm{Ni}, \mathrm{P}, \mathrm{Ce}$ were found its characteristic peak position in Fig.1. It means the coatings contain the element of $\mathrm{Ni}, \mathrm{P}$ and $\mathrm{Ce}$.

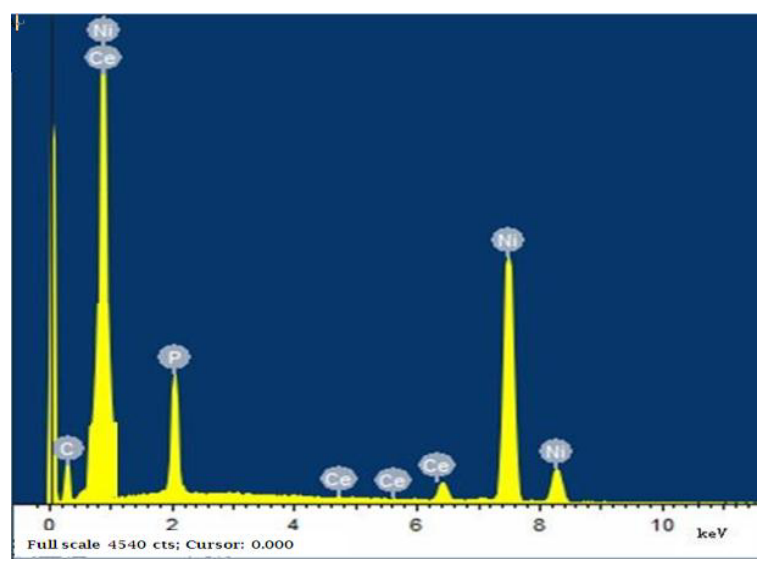

Fig.1 EDX pattern of the Ni-P coating with cerium concentration of $0.12 \mathrm{~g} \cdot \mathrm{L}^{-1}$

Fig. 2 shows that XRD spectrum of the Ni-P coating with cerium concentration of $0.12 \mathrm{~g} \cdot \mathrm{L}-1$. At the diffraction angle $(2 \theta)$ is $44.9^{\circ}$, the diffraction peaks appears, the peaks is the nickel (111) characteristic diffraction peaks. It indicates that the surface morphology of the coating which added in rare element cerium is amorphous structure.

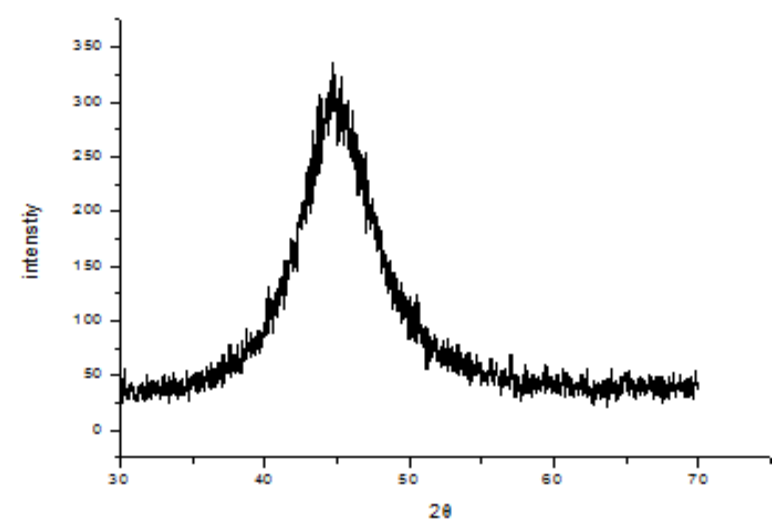

Fig. 2 XRD spectrum of the Ni-P coating with cerium concentration of $0.12 \mathrm{~g} \cdot \mathrm{L}^{-1}$ 


\subsection{Effect of added in rare element cerium on the surface morphology of the coatings}

Fig. 3 shows that the surface morphology of the electroless coatings at the rare element cerium concentration of $0 \sim 0.16 \mathrm{~g} \cdot \mathrm{L}^{-1}$ in the plating bath. As the increasing content of cerium, the surface morphology has the distribution of Ni-P cells on the coatings. Without the cerium added, the average sizes of the Ni-P cells on the surface coatings is about $4 \mathrm{~nm}$, a little mount of small cells distribute at the boundary of large cells, the large small cells has large percent. But with the increasing the content of $\mathrm{Ce}$ in the plating bath, the mount of small cells is increasing, and the surface morphology is gradually refined, the size of cells become smaller. At the $\mathrm{Ce}$ concentration of $0.12 \mathrm{~g} \cdot \mathrm{L}^{-1}$ in the deposition solutions, the surface morphology of the electro-less coatings has a well quality coating, the size of cells is about $2 \mathrm{~nm}$. Due to the special chemical properties of rare element cerium in the chemical deposition, it can produce dispersed particles and hinders grain growth. As increasing the concentration of cerium make the grain of the coating surface small, and the coating surface firming. The rare element cerium refines to microstructure of the Ni-P coatings, and produces smooth and mirror-like coatings.

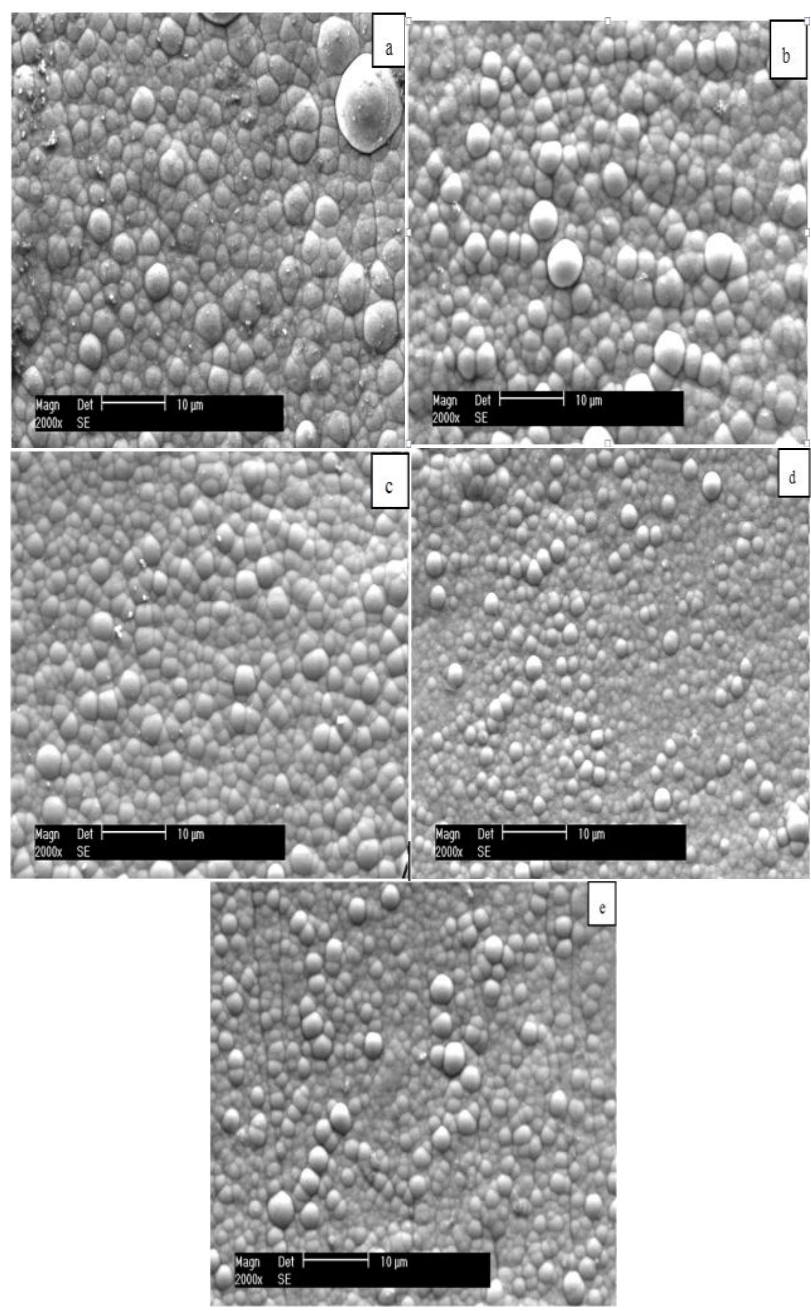

Fig.3 SEM images of samples with different cerium concentration: (a)Ce- $0 \mathrm{~g} \cdot \mathrm{L}^{-1}$; (b)Ce- $0.04 \mathrm{~g} \cdot \mathrm{L}^{-1}$; (c) Ce- $0.08 \mathrm{~g} \cdot \mathrm{L}^{-1}$; (d) $\mathrm{Ce}-0.12 \mathrm{~g} \cdot \mathrm{L}^{-1}$; (e) $\mathrm{Ce}-0.16 \mathrm{~g} \cdot \mathrm{L}^{-1}$

\subsection{Hardness and Adhesive force of the coating}

The hardness of the Ni-P coating test, using the HX-200 Vickers diamond indenter micro-hardness tester, load time is $15 \mathrm{~s}$, each sample measured 10 points, got the average force. The micro-hardness test result shows the Ni-P coatings have the mean hardness from HV570 to HV611, as seen from Fig.4, respectively. After the addition of rare element cerium, coating hardness increasing rate is a positive linear correlation. At a concentration of $0.15 \mathrm{~g} \cdot \mathrm{L}^{-1}$, it has been the highest hardness value. High hardness of the coating has a better application in industry.

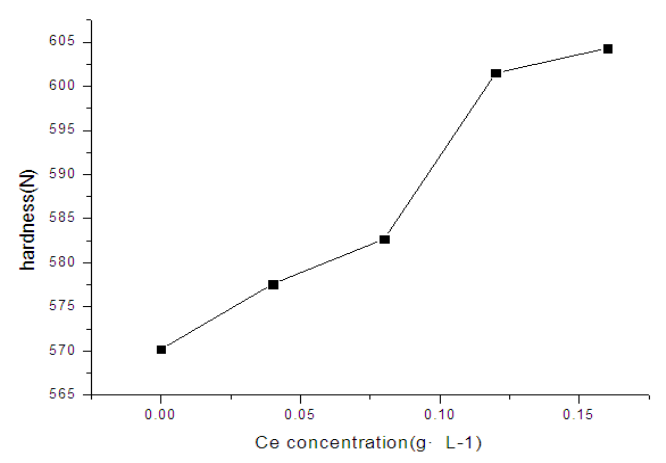

Fig.4 The effect of Ce concentration on hardness of the coatings Adhesive force of the coating was tested by the Revetest scratch tester, the load force of the Revetest scratch tester ranges from $0 \mathrm{~N}$ to $120 \mathrm{~N}$. In the tester parameter settings, the load speed is $200 \mathrm{~N} \cdot \mathrm{m}^{-1}$. The coatings average adhesion force of each sample was measured three times in the test.

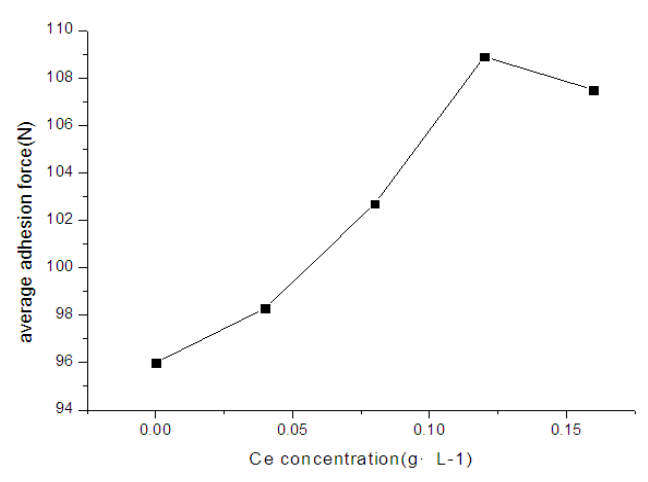

Fig.5 The effect of Ce concentration on average adhesion force of the coatings

As shown in Fig.5, added the rare element cerium of the coatings have a higher average adhesion force than without added cerium. The amorphous Ni-P coatings average adhesion force is basically increasing in graph. Amorphous Ni-P coating adhesion force achieved range from $96 \mathrm{~N}$ to $108 \mathrm{~N}$. At the rare element cerium concentration of $0.12 \mathrm{~g} \cdot \mathrm{L}^{-1}$, average adhesion force get a maximum value.

As for the rare element cerium added, hardness and adhesive force of the amorphous Ni-P coatings are increasing. From the Fig.5, with the increasing the content of $\mathrm{Ce}$ in the plating bath, the mount of small cells is increasing, and the surface morphology is gradually refined, the size of cells become smaller. The proper rare 
element cerium has an effect on changing the hardness and adhesive force of the amorphous Ni-P coatings.

\subsection{The effect of the rare element $\mathrm{Ce}$ on deposition rates of the Ni-P coatings}

The deposition rate of the Ni-P coatings was calculated by the following formula:

$$
v=\frac{m_{1}-m_{0}}{t \cdot A \cdot \rho} \times 10^{4}
$$

Where $v$ is the corrosion rate of the composites $\left(\mathrm{mg} \cdot \mathrm{cm}^{-2}\right) ; m_{0}$ and $m_{1}$ are the mass of the sample before and after deposition(mg); $t$ is the deposition time; $A$ is area of the simple $\left(\mathrm{cm}^{2}\right) ; \rho$ is density of the Ni-P coatings, $\rho$ is replaced by $7.9 \mathrm{~g} \cdot \mathrm{cm}^{-3}$.

Fig.6 shows that the effect of $\mathrm{Ce}$ content on deposition rates of the $\mathrm{Ni}-\mathrm{P}$ coatings in curves. It is seriously observed that with the addition of rare element cerium increases the deposition rates of the coatings firstly increases with the cerium concentration, at the Ce concentration of $0.04 \mathrm{~g} \cdot \mathrm{L}^{-1}$, the deposition rates reach on a largest point at $15.3 \mu \mathrm{m} \cdot \mathrm{h}^{-1}$, and deposition rates decreases with the increasing $\mathrm{Ce}$ concentration. The rare element Ce reduces the activity energy of the deposition reaction, and also reduces the value of the critical nucleation, increases the nucleation rate, promote the reaction rate. As an increasing concentration of cerium, the Ni-P coatings deposition rates increases.

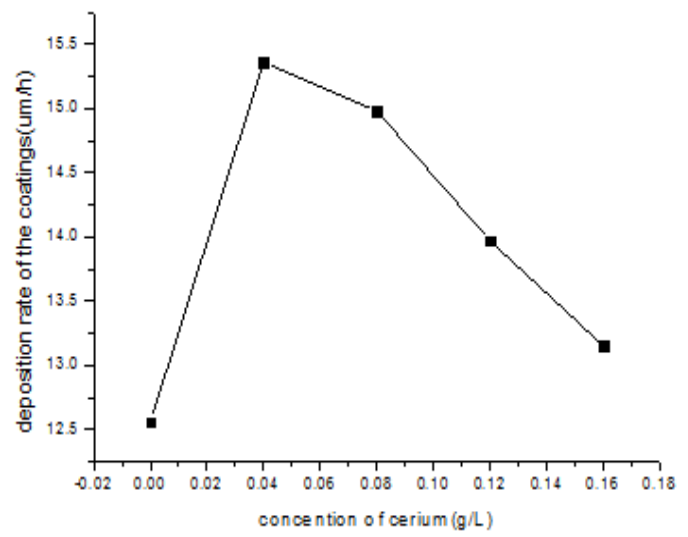

Fig. 6 Effect of cerium concentration on deposition rates of the coatings

\subsection{The effect of the rare element $\mathrm{Ce}$ on phosphorus content of the Ni-P coatings}

Fig. 7 shows that the rare element Ce concentration in the plating bath has an effect on phosphorus content of the $\mathrm{Ni}-\mathrm{P}$ coatings. With the Ce concentration increased, the phosphorus content of the Ni-P coatings has a trend of going up, reach at a point, and then cut down. At the Ce concentration of $0.12 \mathrm{~g} \cdot \mathrm{L}^{-1}$, the morphology content that reach at a maximum value is the percent of 13.5. Corrosion resistance for Ni-P coatings is superior to plating $\mathrm{Ni}$, which contribute to higher phosphorus content in coatings. The rare element $\mathrm{Ce}$ is related to the active hydrogen ion comes out in the solution, that is to say, more $\mathrm{H}_{2} \mathrm{PO}_{2}^{-}$change into active hydrogen ion and phosphorus co-deposition in forming the Ni-P coatings. But addition the amount of rare element $\mathrm{Ce}$ is over 0.12 $\mathrm{g} \cdot \mathrm{L}^{-1}$, the promotion of the rare element is decreasing, and the higher active hydrogen ion will make the plating bath unstable.

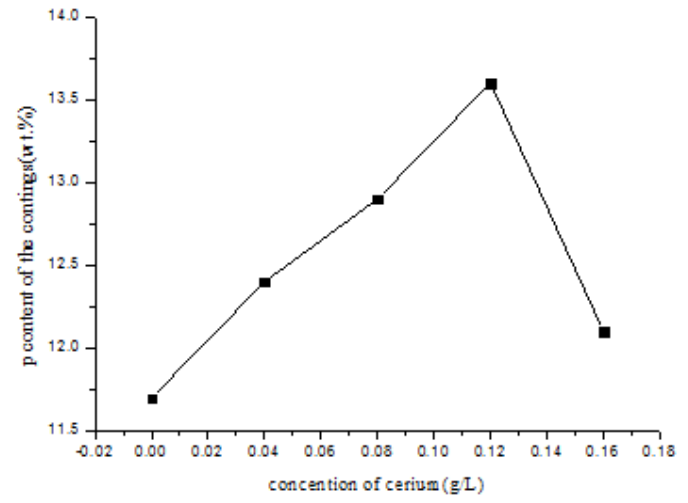

Fig 7 Effect of cerium concentration on the phosphorus content in the coatings

\subsection{Corrosion rates of the Ni-P coatings}

Fig. 8 shows that the rare element Ce concentration in the plating bath has an effect on corrosion rates of the Ni-P coatings. The sample of Ni-P coating had groundwater immersion tests to get the corrosion rates. Compared with not added the rare element $\mathrm{Ce}$ in the plating bath, the coatings corrosion rates of added Ce becomes lower. At the Ce concentration of $0.12 \mathrm{~g} \cdot \mathrm{L}^{-1}$, the coatings corrosion rates has a minimum value in the groundwater immersion test. The coatings corrosion rates cut down with the rare element $\mathrm{Ce}$ concentration increase. Surface defects always exist in the metal coatings, such as pinhole and pore, and corrosion firstly appeared in these defects. Specifically, defects have larger corrosion current, and coating corrosion will spread along the defects the vertical direction of the coating surface to the depths ${ }^{[12]}$.

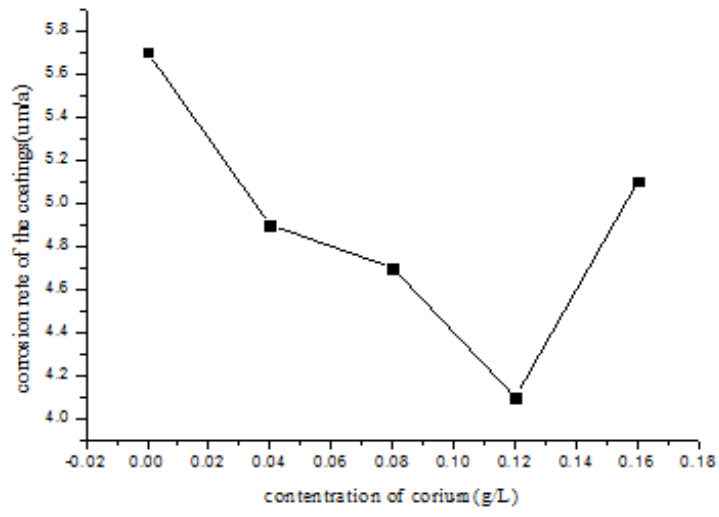

Fig.8 Corrosion rates of the coatings with different $\mathrm{Ce}$ concentration in groundwater

\subsection{The Ce concentration affect on the coating porosity}

Fig.9 shows that the $\mathrm{Ce}$ concentration in the plating solution has an effect on the coating porosity. It indicated higher phosphorus content in the coatings having a lower porosity. Compared with the Ni-P coatings without added 
the rare element cerium, the addition of little rare element cerium amorphous Ni-P coatings has a lower porosity in experiment. The porosity of the addition of little rare element cerium amorphous Ni-P coatings are less than $0.25 \mathrm{~N} \cdot \mathrm{cm}^{-2}$, as expected.

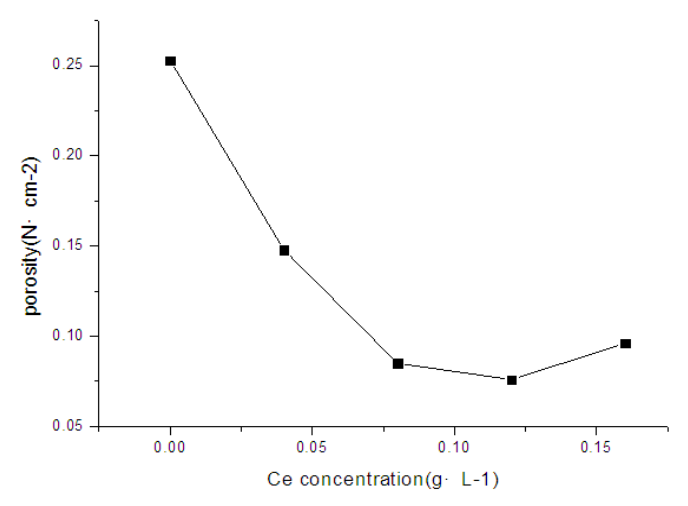

Fig.9 The Ce concentration affect on the Ni-P coating porosity

\section{Conclusions}

1) The Ni-P coatings contain the element of $\mathrm{Ni}, \mathrm{P}$ and $\mathrm{Ce}$, and the surface morphology of the coating is amorphous structure. As the increasing the content of $\mathrm{Ce}$ in the plating bath, the mount of small cells is increasing, and the surface morphology is gradually refined, the size of cells become smaller.

2) Priority of discharging in activation for substitution of rare element cerium can improve the electrode interface coordination ions in the electro-plating bath. As an increasing concentration of cerium, the Ni-P coatings deposition rates increase, the size of cells in the surface microstructure become small and cell-like structure closely surrounded in the coating.

3) As for the addition of the rare element cerium, the phosphorus content increases of the Ni-P coatings. The rare element cerium reduces the activity energy of the deposition reaction, and also reduces the value of the critical nucleation, increases nucleation ability, promote the reaction rate, and corrosion rates cut down in groundwater immersion test of the Ni-P coatings.

4) Hardness and adhesive force of the Ni-P coating have the similarity to addition of rare element cerium electroplating solution. The amorphous Ni-P coatings average adhesion force is basically achieved ranging from $96 \mathrm{~N}$ to $108 \mathrm{~N}$, and the amorphous Ni-P coatings hardness rise from HV570 to HV611.

5) With the addition of rare earth cerium, adhesion force of the coating increases. Because the coating formed a small amount of nickel amorphous structure of cerium phosphate, nickel phosphorus fill the gap in the surface of the cell-like body formed; while under the effect of increasing the stability of the bath, cerium reduces the pinholes of the coatings during deposition in the generation of the coatings, and dense coating, bonding force is correspondingly.

6) The corrosion rates cut down in groundwater immersion test of the Ni-P coatings because of the addition of the rare element cerium. At the cerium concentration of $0.12 \mathrm{~g} \cdot \mathrm{L}^{-1}$ in the plating bath, the coatings corrosion rates has a minimum value, is 4.1 $\mathrm{um} \cdot \mathrm{h}-1$, in the groundwater immersion test. Further, the porosity of the addition of little rare element cerium amorphous Ni-P coatings is less than the Ni-P coatings.

\section{References}

1. Brenner A, Riddell GE. Nickel plating by chemical reduction. US Patent: US2532282; 1950.

2. Y.S Huang, F.Z. Cui. Effect of complexing agent on the morphology and microstructure of electro-less deposited Ni-P alloy, Surface \& Coatings Technology Vol. 201(2007), p.5416

3. Li Jianzhong, Tian Yanwen, Li Ying et al. Effect of rare earth addition on structure and properties of $\mathrm{Ni}$ $\mathrm{P}$ coating on $\mathrm{SiCp} / \mathrm{Al}$ composites. Journal of Rare Earths, 2010, 28(5):769-773.

4. Wang Jianfei, Tian Jintao, Liu Xuezhong et al. Effect of polytetrafluoroethylene content on electrochemical anticorrosion behaviors of electroless deposited Ni-P and Ni-Ppolytetrafluoroethylene coatings in seawater $[\mathrm{J}]$. The Solid Films, 2011, 519: 5905-5911.

5. $\mathrm{Hu} \mathrm{C}, \mathrm{Bai} \mathrm{A}$. Influences of the phosphorous content on physiochemical properties of nickel phosphorous deposits. Materials and Chemistry and Physics, 2003, 80(2):215

6. H.S. Ashassi, H. Dolati, N.A. Parvini, J. Manzoori, Appl. Surf. Sci.185 (2002)155.

7. F. Rosalbino, E. Angelini, S. De Negri et al. Intermetallics11 (2003)435.

8. Jianzhong Li, Yanwen Tian, Ying Li, et al. Effect of rare earth addition on structure and properties of $\mathrm{Ni}$ $\mathrm{P}$ coating on $\mathrm{SiCp} / \mathrm{Al}$ composites. Joural of Rare Earths, 2010,28,769.

9. Burchardt T. The effect of deposition temperature on the catalytic activity of Ni-P alloys toward the hydrogen reaction [J]. Int J Hydrogen Energy, 2002, 27: 323-326

10. Sharma A. K., Suresh M R, Bho jraj H, et al. Electro less nickel plating on magnesium alloy [J]. Metal Finishing, 1998, 96(3): 10 18.

11. Decroly A, Petitjean J P. Study of the deposition of cerium oxide by conversion on to aluminum alloys[J] .Surface and Coatings Technology, 2005, 194 (1): 1-9.

12. Weiwei Li, Lei Liu, Cheng Zhong, et al. Effect of carbon fiber surface treatment on $\mathrm{Cu}$ electro deposition: The electrochemical behavior and the morphology of $\mathrm{Cu}$ deposits. Journal of Alloys and Compounds, 2011, 509:3532-3536.

13. Ali Lei, Lajun Feng. Study of complex accelerators action on electro-less nickel-phosphorus alloys[J]. Electroplating and Finishing. 2008, 27(5):19-21

14. Ximei Fan, Huiguang Zhang, Jun Hao. Gradient eletro-less Ni-P alloy coating preparation and corrosion resistance[J]. Journal of Southwest Jiaotong University, 2010,45(3) :389-392 